\title{
Effects of multidisciplinary inpatient rehabilitation for chronic back or neck pain: a register-linkage study of sickness absences and analgesic purchases in an occupational cohort
}

H Suoyrjö, K Hinkka, T Oksanen, M Kivimäki, T Klaukka, J Pentti and J Vahtera

Occup. Environ. Med. 2008;65;179-184; originally published online 16 Oct 2007; doi:10.1136/oem.2007.033753

Updated information and services can be found at:

http://oem.bmj.com/cgi/content/full/65/3/179

\section{References}

These include:

This article cites 10 articles, 4 of which can be accessed free at: http://oem.bmj.com/cgi/content/full/65/3/179\#BIBL

1 online articles that cite this article can be accessed at: http://oem.bmj.com/cgi/content/full/65/3/179\#otherarticles

Rapid responses

Email alerting service
You can respond to this article at:

http://oem.bmj.com/cgi/eletter-submit/65/3/179

Receive free email alerts when new articles cite this article - sign up in the box at the top right corner of the article

Notes 


\title{
Effects of multidisciplinary inpatient rehabilitation for chronic back or neck pain: a register-linkage study of sickness absences and analgesic purchases in an occupational cohort
}

\author{
H Suoyrjö, ${ }^{1}$ K Hinkka, ${ }^{2}$ T Oksanen, ${ }^{3}$ M Kivimäki, ${ }^{3,4}$ T Klaukka, ${ }^{5}$ J Pentti, ${ }^{3}$ J Vahtera ${ }^{3}$
}

\begin{abstract}
${ }^{1}$ Petrea, Rehabilitation Centre, Turku, Finland; ${ }^{2}$ Research Department, Social Insurance Institution of Finland, Turku, Finland; ${ }^{3}$ Finnish Institute of Occupational Health, Turku, Finland; ${ }^{4}$ Department of Epidemiology and Public Health, University College London, UK;

${ }^{5}$ Research Department, Social Insurance Institution of Finland Helsinki, Finland
\end{abstract}

Correspondence to: Dr H Suoyrjö, Hospital District of South Ostrobotnia, Hanneksenrinne 7, F1-60220 Seinäjoki, Finland; heikki.suoyrjo@epshp.fi

Accepted 16 August 2007

Published Online First

16 October 2007

\begin{abstract}
Objective: To determine the effects of multidisciplinary in-patient rehabilitation for chronic back or neck pain on sickness absences and analgesic purchases.

Design: A prospective observational study.

Setting: 10 towns in Finland.

Participants: 34838 local government employees, including 418 participants in rehabilitation for chronic back pain and 195 participants in rehabilitation for chronic neck pain between 1994 and 2002.

Main outcome measures: The annual rates of short (13 days), long ( $>3$ days), and very long ( $>21$ days) sickness absences and the defined daily doses (DDD) of prescribed analgesics.

Results: The rate of very long ( $>21$ days) sickness absence among the chronic back pain rehabilitees was 3.03 -fold (95\% Cl 2.55 to 3.60 ) compared to the nonrehabilitees in the year before rehabilitation. This ratio declined to $1.88(95 \% \mathrm{Cl} 1.65$ to 2.37$)$ three years after rehabilitation. No further decline in the rate of very long sickness absence was observed in the subsequent years. For chronic neck pain rehabilitees, no evidence of the effectiveness of rehabilitation on sickness absence was found. In relation to consumption of analgesics, the mean rate of DDDs declined among the back and neck pain rehabilitees after rehabilitation compared to the nonrehabilitees.
\end{abstract}

Conclusions: Multidisciplinary in-patient rehabilitation for chronic back pain may decrease the risk of very long sickness absence for three years. In relation to rehabilitation for chronic neck pain, no changes in sickness absences were found.

It has been estimated that in most developed countries $0.5-2 \%$ of gross national product is attributed to the costs of back pain in terms of work loss, sickness absence and other indirect costs. ${ }^{1}$ The risk of long-lasting or permanent work disability among patients with chronic back and neck pain is high. In the UK, for example, $20 \%$ of all incapacity benefit claims filed were due to musculoskeletal disorders in 2006. ${ }^{2}$ In Finland and Sweden, over $30 \%$ of new long-term sick leaves and disability pensions have been granted on account of musculoskeletal disorders, mostly back or neck pain, during the past few years. ${ }^{3-5}$ Furthermore, part of the burden related to chronic back or neck pain results from the increasing expenditure on analgesics, which represents approximately $10 \%$ of all direct costs related to chronic back and neck pain in the UK and 6\% in Sweden. ${ }^{6}$
Multidisciplinary, active, exercise-oriented inpatient rehabilitation for chronic back or neck pain is widely adopted in the national rehabilitation regimes in many countries, including Finland. ${ }^{78}$ The effectiveness of such rehabilitation is, however, unclear, and most of the previous studies are based on short follow-up times and they lack objective outcome measures. ${ }^{9}$ Heterogeneity in terms of the contents of rehabilitation further complicates the interpretation of results.

We conducted an eight-year register-based follow-up study in a large cohort of local government employees who had participated in multidisciplinary in-patient rehabilitation for chronic back or neck pain. The objective of the study was to assess the effects of musculoskeletal rehabilitation in a real-life setting. We used sickness absences and purchases of prescribed analgesics as measures of functional status among the rehabilitees.

\section{METHODS}

\section{Participants}

Data were drawn from the ongoing Finnish 10 Town Study, which is exploring the health of fulltime public sector employees in 10 towns in Finland. ${ }^{10}$ The eligible population consisted of 67106 local government employees who had been employed for at least 10 months in one year between 1994 and 2002. Of this population, 1251 employees had been granted inpatient multidisciplinary rehabilitation on account of musculoskeletal disorders. To retain focus on work context, we excluded all those who had been at work $<3$ months in the year the rehabilitation started plus or minus three years $(n=29)$ or those who were not in the service four years after rehabilitation $(n=349)$. We also excluded those rehabilitees who had been granted rehabilitation for musculoskeletal reasons other than chronic back or neck pain $(n=260)$. All other permanent employees, excluding those who had been at work $<3$ months in a randomly selected year plus or minus three years between 1994 and $2002(n=3714)$, served as a control group. Thus, the final cohort consisted of 418 employees participating in chronic back pain rehabilitation, 195 employees participating in chronic neck pain rehabilitation, and 34225 employees with no multidisciplinary in-patient musculoskeletal rehabilitation (the non-rehabilitees). The proportions of women among the back and neck pain rehabilitees were $74 \%$ and $89 \%$, respectively, and among the non-rehabilitees $72 \%$. 
A subgroup of employees who were in the service of the towns six years after rehabilitation (250 back pain rehabilitees, 133 neck pain rehabilitees and 23379 non-rehabilitees) was followed for 10 years.

The ethics committee of the Finnish Institute of Occupational Health approved the study.

\section{Rehabilitation for chronic back and neck pain}

We used the participants' personal identification codes (a unique number that all Finns receive at birth and is used for all contacts with the social welfare and healthcare systems) to retrieve data from the rehabilitation register kept by the Social Insurance Institution of Finland (SII). This national register provides data on all rehabilitation granted by the SII, including the type of rehabilitation, year of granting, and main diagnosis for rehabilitation.

The participants in rehabilitation for chronic back and neck pain had been selected by the local SII offices based on certificates given by the treating physicians and on respective diagnoses, namely ICD-9: 7213, 7221, 7225, 7227, 7228, 72407245, 732, 737; ICD-10: M40, M41, M43.0-2, M47.82, M48.0-1, M51, M53.2-3, M54.3-9, and S33 for chronic back pain, and ICD-9: 7210, 7211, 7220, 7224, 723; ICD-10: G44.2, M50, M53.0-1, M54.2, M75.8, and S13 for chronic neck pain.

For the implementation of the rehabilitation for chronic back and neck pain provided by the SII, the individual rehabilitation institutions are obliged to follow detailed standard guidelines. In accordance with these guidelines, chronic back or neck pain rehabilitation was given on courses with 8-12 participants in each. A course was divided into two or three in-patient periods within one year, 15-18 days in total. The rehabilitation was multidisciplinary pain management in character and, compared to functional restoration programmes introduced by Mayer et $a l,{ }^{11}$ relatively light in strenuousness. The goal was to enhance the rehabilitees' self-care abilities, to instruct and motivate them in physical activities, and to improve pain management in order to promote their capability to work. The multidisciplinary rehabilitation team included a physician, a psychologist, a physiotherapist, a social worker and a nurse.

\section{Sickness absence}

To obtain data on all sickness absences in 1991-2006, we linked the participants' personal identification codes to the records on sickness absences kept by their employers. The procedure for recording sick leave in the Finnish public sector is reliable. ${ }^{12}$ For any absences longer than three days, a medical certificate is required. The indices of sick leave used in this study included the annual rates of short-term ( $\leqslant 3$ days) and long-term (>3 days) absences. We also examined sick leave lasting $>21$ days, because long-standing illnesses, such as musculoskeletal disorders, show a stronger association with longer durations of sickness absence. ${ }^{13}$ The number of contracted days represented the "days at risk", from which the number of days absent from work for reasons other than sickness was subtracted (sick leaves are not recorded during these periods).

To assess the rate of sickness absence, we divided the annual number of sickness absence episodes by days at risk in a given year. We determined all sickness absences for an eight-year period covering three years prior to rehabilitation ("pre-years"), the actual year of rehabilitation, and four years after rehabilitation ("post-years"). For the non-rehabilitees, the sickness absences were linked to the data in the same manner as for the rehabilitees, with pre- and post-years based on a randomly assigned year.

\section{Purchase of analgesics}

To identify analgesic treatment during each year of follow-up, we used prescription data from the nationwide SII register that comprises all reimbursed out-patient prescriptions. The medicines are classified according to the Anatomical Therapeutic Chemical (ATC) classification code. ${ }^{14}$ The national sickness insurance scheme covers the entire population in Finland.

From the register, we retrieved data on all the prescriptions in the ATC categories N02 (opioids and other analgetic drugs) and M01A (non-steroidal anti-inflammatory drugs) and identified the number of defined daily doses (DDD) for each purchase over a period from 1 January 1994 to 31 December 2006. The DDD is the assumed average maintenance dose per day for a drug used for its main indication in adults. Thus, the DDD data presented in the following give an estimate of annual analgesic consumption.

\section{Disability pensions}

To estimate the effect of health-related selection on our results, we used participants' personal identification codes to collect data on disability pensions from the national pension register kept by the Finnish Centre of Pensions. This register provides virtually complete population retirement data. The dates and causes of disability pensions granted for all participants in between 1 January 1994 and 31 December 2006 were obtained.

\section{Other variables}

From the employers' records, we derived information on gender, age, occupational status (higher-grade non-manual, lower-grade non-manual, and manual employees), and type of work contract (permanent, non-permanent) for the entire cohort in the year of rehabilitation.

\section{Statistical analysis}

The differences in baseline characteristics between the rehabilitees and non-rehabilitees were analysed with the $\chi^{2}$ test and analysis of variance. To examine the effectiveness of rehabilitation, we used information on repeated observations of annual sickness absence and analgesic prescriptions in relation to the start of rehabilitation, and analysed these count data with repeated measures Poisson regression analysis during the followup period. The repeated measurements of sickness absence and prescribed analgesic purchases of the same subject are correlated observations. To take into account this correlation, we applied the generalised estimating equations (GEE) approach. ${ }^{15}$ Regression models for sickness absences were based on Poisson distribution and those for analgesics on negative binomial distribution.

We calculated the rate ratios for short (1-3 days), long (>3 days) and very long (>21 days) sickness absence spells and their $95 \%$ confidence limits (CL) in rehabilitees compared with non-rehabilitees for eight different time periods (from three years before the rehabilitation to four years after the rehabilitation). We also calculated the mean annual number of DDDs for the purchases of the prescribed analgesics in the three years preceding rehabilitation, during the year of rehabilitation, and in the subsequent four years. The analyses were adjusted for gender, age, occupational status, type of employment contract and year of rehabilitation. We also tested the difference in linear trends between the rehabilitees and non-rehabilitees by apply- 
Table 1 Characteristics of the participants. Figures are numbers (column percentages in parentheses) unless otherwise stated

\begin{tabular}{|c|c|c|c|}
\hline & $\begin{array}{l}\text { Back pain rehabilitees } \\
(n=418)\end{array}$ & $\begin{array}{l}\text { Neck pain rehabilitees } \\
(n=195)\end{array}$ & $\begin{array}{l}\text { Non-rehabilitees } \\
(\mathrm{n}=34225)\end{array}$ \\
\hline \multicolumn{4}{|l|}{ Gender } \\
\hline Men & $108(26)$ & $21(11)$ & $9734(28)$ \\
\hline Women & $310(74)$ & $174(89)$ & $24491(72)$ \\
\hline Mean (SD) age (years) & $48.2(6.5)$ & $48.7(5.5)$ & $43.8(8.0)$ \\
\hline \multicolumn{4}{|l|}{ Occupational status } \\
\hline Higher grade non-manual & $67(16)$ & 37 (19) & $10810(32)$ \\
\hline Lower grade non-manual & $184(44)$ & $97(50)$ & $14684(43)$ \\
\hline Manual & $167(40)$ & $61(31)$ & $8731(25)$ \\
\hline $\begin{array}{l}\text { Short }(\leqslant 3 \text { days) sickness absence spells before } \\
\text { rehabilitation (rate/person-year) }\end{array}$ & 1.53 & 1.57 & 1.14 \\
\hline $\begin{array}{l}\text { All long (>3 days) sickness absence spells before } \\
\text { rehabilitation (rate/person-year) }\end{array}$ & 1.45 & 1.02 & 0.62 \\
\hline $\begin{array}{l}\text { Very long sickness absence spells (>21 days) before } \\
\text { rehabilitation (rate/100 person-years) }\end{array}$ & 26.8 & 15.4 & 9.5 \\
\hline $\begin{array}{l}\text { Consumption of prescribed analgesics before } \\
\text { rehabilitation (DDD/person-year) }\end{array}$ & 17.6 & 17.6 & 7.1 \\
\hline
\end{tabular}

ing a Poisson regression model with an interaction term (time $\times$ rehabilitation) and treating time as a continuous variable in the analyses.

Finally, the role of health selection in the results was studied with logistic regression models comparing odds ratios for disability pension among the excluded rehabilitees who were lost to follow-up with those included rehabilitees who remained in the service of the towns during the entire follow-up.

All the analyses were performed with the SAS 9.1.3 statistical software (SAS Institute, Inc, Cary, NC, USA) applying the GENMOD procedure.

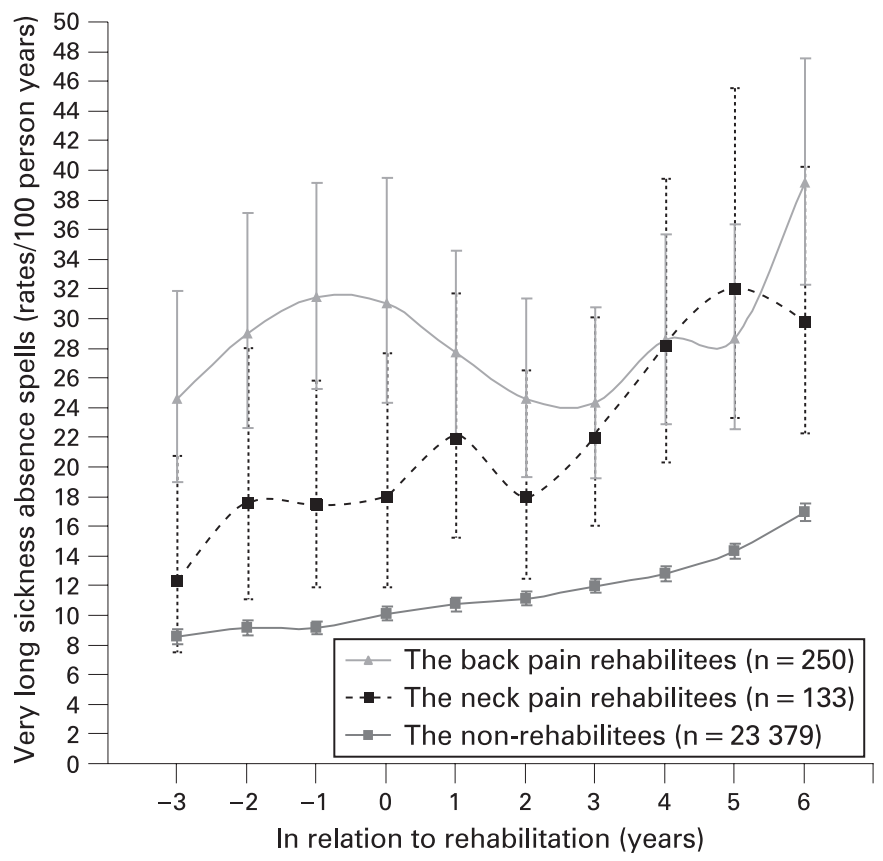

Figure 1 Annual rate (95\% Cl) of very long ( $>21$ days) sickness absence spells among the chronic back and neck pain rehabilitees and the non-rehabilitees adjusted for sex, age, occupational status and the rehabilitation year in the subgroup of participants in service six years after rehabilitation.

\section{RESULTS}

The rehabilitees were older, predominantly female and more often in manual occupations than the non-rehabilitees. We recorded 7400 short and 9066 long spells of sickness absence for the rehabilitees and 318933 short and 214879 long spells for the non-rehabilitees during the mean follow-up time of 7.2 years (SD 1.2) for the rehabilitees and 6.9 years (SD 1.5) for the non-rehabilitees. The average rates of short spells, all long spells and very long spells were $1.54,1.33$ and 0.25 per person year for the rehabilitees and $1.17,0.69$ and 0.12 per person year for the non-rehabilitees, respectively. Among the rehabilitees the mean rate of very long sickness absence spells was 15-27 per 100 person years and the DDDs of purchased analgesics 18 per person year before the rehabilitation. The corresponding rates among the non-rehabilitees at the same time were 10 and 7 , respectively (table 1 ).

Table 2 shows the rate ratios of sickness absence spells and purchases of prescribed analgesics as DDDs during the eightyear follow-up period (including three pre-rehabilitation years and four post-rehabilitation years). Compared to the nonrehabilitees, the rate ratio for all long spells increased before rehabilitation both among the back pain and the neck pain rehabilitees. Among the back pain rehabilitees, long spells turned to a decline after the rehabilitation (difference in trend compared to the non-rehabilitees $p=0.0017)$. This decline was most obvious in three years after rehabilitation and for the very long sick leaves. In the year before rehabilitation, the rate of very long absences among the back pain rehabilitees was 3.0fold compared to that among the non-rehabilitees, but in the third year after the rehabilitation, the corresponding rate ratio was 1.9-fold. Among the neck pain rehabilitees, no decline in sickness absence after rehabilitation was observed. As for the short spells, no significant change in sickness absence after rehabilitation for back pain or neck pain was observed.

The mean DDDs of prescribed analgesics were significantly higher among the back and neck pain rehabilitees compared to the non-rehabilitees through the follow-up. In the year of rehabilitation the DDDs of analgesic purchases were 2.9 times higher among rehabilitees than among non-rehabilitees. However, there was a significant declining trend in the consumption of analgesics among rehabilitees compared with non-rehabilitees. For example, in the fourth year after rehabi- 


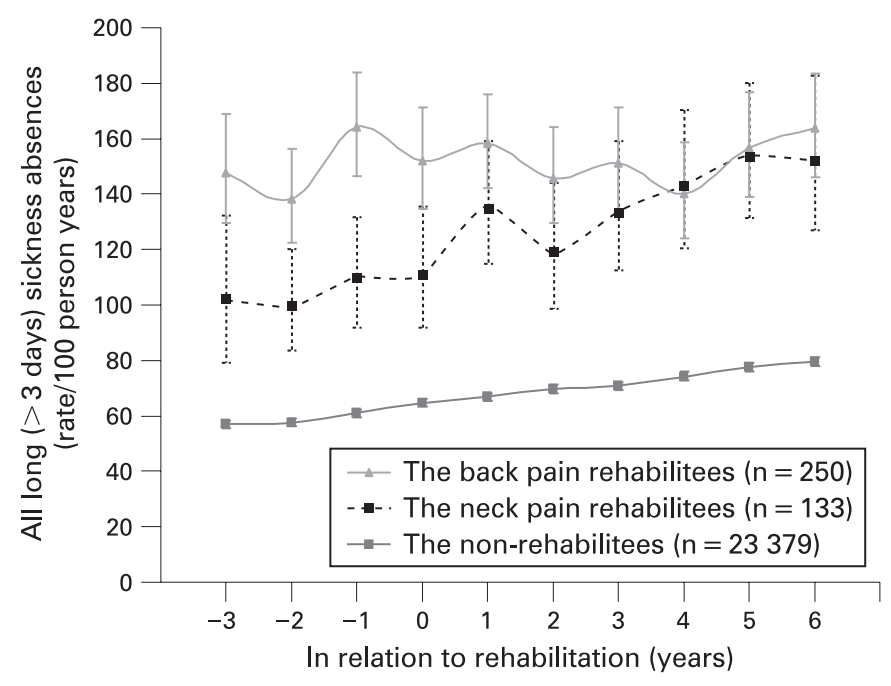

Figure 2 Annual rate $(95 \% \mathrm{Cl}$ ) of all long ( $>3$ days) sickness absence spells among the chronic back and neck pain rehabilitees and the nonrehabilitees adjusted for sex, age, occupational status and the rehabilitation year in the subgroup of participants in service six years after rehabilitation.

litation the rate ratio of DDDs between rehabilitees and nonrehabilitees was 1.8 (95\% CI 1.3 to 2.4 ) (table 2).

We found no evidence of subgroup differences in the effects of back pain rehabilitation on the very long sick leaves by gender, age group $(<50$ or $\geqslant 50$ years), or occupational status (nonmanual or manual) (all $\mathrm{p}$ for rehabilitation $\times$ subgroup $\times$ time interactions $>0.6$, data not shown).

Figures 1 and 2 show the rates of very long ( $>21$ days) and all long ( $>3$ days) sickness absence spells, respectively, for the subgroup of the rehabilitees and the non-rehabilitees followed for six years after rehabilitation. The figures show that the decline in very long sickness absence spells after rehabilitation for back pain continues three years and for all long spells four years.

Compared to the rehabilitees included in the study, the excluded 349 rehabilitees not in the service of the towns at the end of the follow-up year 8 had 1.7 (95\% CI 1.6 to 1.9$)$ times higher rate of very long sickness absence spells and 1.5 (95\% CI 1.0 to 2.3) times more purchases of prescribed analgesics in the four years before rehabilitation (adjusted for sex, age, occupational status and the rehabilitation year). In the four years after rehabilitation, $15.8 \%$ of the excluded back pain rehabilitees and $13.5 \%$ of the excluded neck pain rehabilitees at work in the beginning of follow-up were granted disability pension. Among the excluded non-rehabilitees the corresponding figure was $3.2 \%$. After adjustment for demographic characteristics, odds ratios for disability pension among the excluded back and neck pain rehabilitees compared to the excluded non-rehabilitees were 4.3 (95\% CI 3.4 to 5.3 ) and 3.4 (95\% CI 2.4 to 4.7 ), respectively. The majority of disability pensions granted to the excluded back and neck pain rehabilitees and the nonrehabilitees were due to musculoskeletal disorders (64\%, 44\% and $40 \%$, respectively). The corresponding figures for disability pensions granted due to mental disorders were $23 \%, 20 \%$ and $27 \%$.

\section{DISCUSSION}

This eight-year observational follow-up study found a declining trend in the rate of medically certified sickness absence among

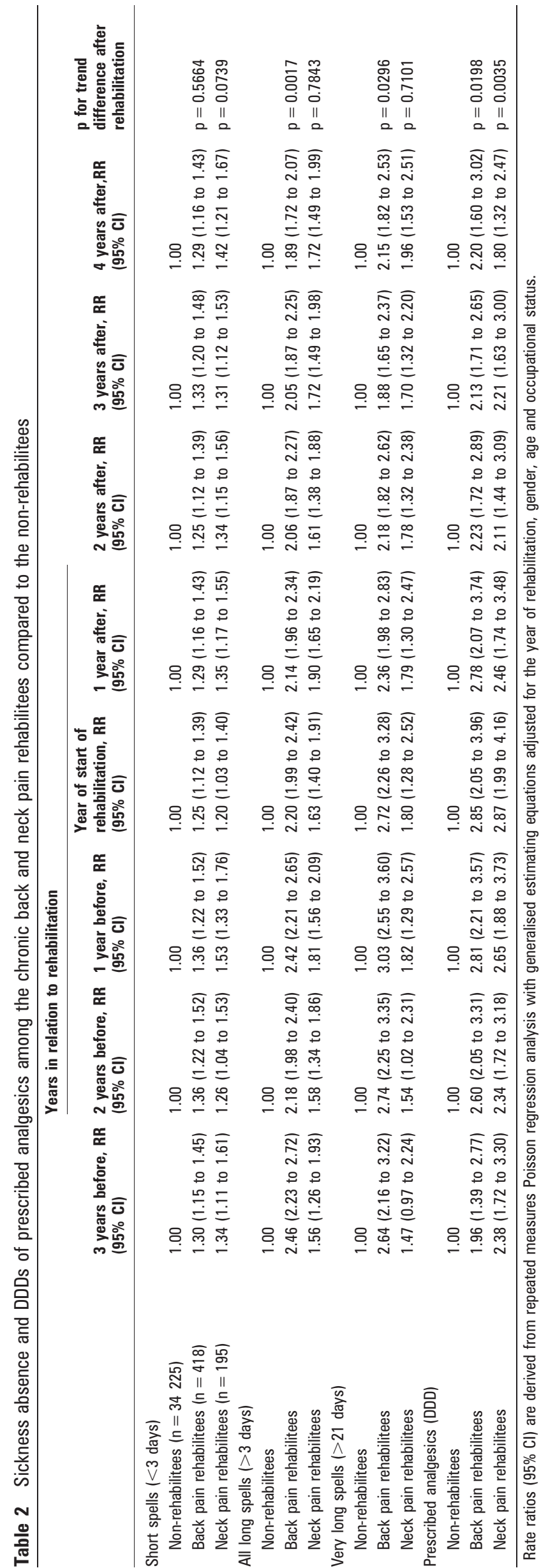


the employees participating in multidisciplinary in-patient pain management rehabilitation for chronic back pain compared with non-rehabilitees. The effect on sickness absence faded out after 3 years and was evident only for sick leaves over 21 days. No corresponding evidence was found for rehabilitation for chronic neck pain. However, in both groups of rehabilitees the purchases of prescribed analgesics compared to the nonrehabilitees declined after rehabilitation.

The strengths of this study are the use of reliable registered data on a large cohort of employees and the long follow-up time. The rehabilitation for chronic back and neck pain was based on standard guidelines. Because all the participants were from the same work organisation, we were able to compare changes in trends in sickness absence and use of analgesics between the rehabilitees and a natural comparison group in a real-life setting.

The major weakness of a non-controlled study, such as ours, is the effect of health selection on the results. In our study the excluded rehabilitees had high rate of sickness absence rate, high consumption of prescribed analgesics prior to rehabilitation and high odds of being granted disability pension during follow-up. This indicates that the included rehabilitees studied by us - that is, those who remained in the service until the end of the followup-were less disabled compared to the rehabilitees who were excluded. It is possible that the significantly falling sickness absence rates observed in this study are true only for employees moderately affected by their back problems, but not among those who were seriously affected and excluded from this study. In such a case, the results reported would be positively skewed.

In agreement with earlier studies suggesting a strong association between chronic musculoskeletal symptoms and subsequent work disability, ${ }^{16}$ the rehabilitees had an increased risk of work disability and increased level of long-term sickness absences, which is a predictor of work disability and exit from work due to disability pension or premature death. ${ }^{12} 1718$ Furthermore, chronic conditions such as musculoskeletal diseases show stronger associations with sickness leaves longer than 21 days than with absences of shorter durations. ${ }^{13}$ Thus, our results indicating a decline in the very long sick leaves (>21 days) after back pain rehabilitation suggest that such rehabilitation is likely to reduce the risk of temporary work disability in a high-risk population. This is an important finding because there is little previous evidence on effective measures to reduce sickness absences caused by musculoskeletal disorders, which are a great burden to organisations and extremely costly to society.

We found that the effectiveness of chronic back pain rehabilitation was exhausted after three years. The time-limited effectiveness of back pain rehabilitation agrees with earlier findings. Bendix et al reported that, in one of the two parallel controlled studies, the effect on disability faded out in two years, while in the other study, the effect seemed to last five years after the multidisciplinary rehabilitation for chronic back pain. ${ }^{19}$ In a Finnish study by Härkäpää et al, the effect of multidisciplinary rehabilitation on low back pain disability faded out after eight months. ${ }^{20}$ A Swedish study by Lindh et al reported on improved work stability after return to work among native Swedes participating in multidisciplinary rehabilitation for non-specific musculoskeletal pain, compared to controls, and this effect lasted three years. ${ }^{21}$ The fact that the present study found no effect of chronic neck pain rehabilitation on sickness absence is in agreement with evidence from smaller-scale studies on disability. ${ }^{72}$

\section{Main messages}

- Multidisciplinary rehabilitation of chronic back pain may decrease the risk of very long sickness absence.

- No effect on sickness absence was found in rehabilitation of chronic neck pain.

- Use of prescribed analgesics showed a declining trend after rehabilitation among rehabilitees compared with nonrehabilitees.

- The effect of back pain rehabilitation on very long sickness absence spells was exhausted after three years.

\section{Policy implications}

- Multidisciplinary inpatient rehabilitation of chronic neck pain is unlikely to be effective.

- Rehabilitation regime of musculoskeletal disorders needs further development.

We measured subjective symptom relief by the mean number of DDDs of prescribed analgesics. ${ }^{14}$ Consequently, we were able to estimate the average number of days treated by pain killers in relation to rehabilitation. The relative rate of analgesic purchases among the rehabilitees showed a decline after rehabilitation in comparison to the non-rehabilitees, though the absolute rates remained essentially the same. This is in line with earlier research reporting favourable trend in subjective symptoms among participants in multidisciplinary back pain rehabilitation. ${ }^{9}$ Given the many biases related to self-reported data, symptom measures may be unreliable in the assessment of the effectiveness of rehabilitation. The more objective measures of the persistence of symptoms, such as use of an analgesic to pain relief, provide probably less biased information. This study confirms reports from earlier studies showing chronic musculoskeletal pain to be persisting and difficult to cure. ${ }^{16}$

In conclusion, multidisciplinary inpatient rehabilitation may reduce the risk of very long sickness absence spells among employees with chronic back pain, but is unlikely to be effective in treatment of employees with chronic neck pain.

Acknowledgements: HS is the principal investigator of the study and had the main responsibility for writing the paper. The study was designed and conducted together with JV. JP supervised the data analyses. KH, MK, TO and TK helped in interpreting the results and writing the paper. HS will act as guarantor.

Funding: This study was supported by the Social Insurance Institution of Finland, the Academy of Finland (Projects 117614, 124271 and 124322), the Finnish Work Environment Fund, and the towns participating in the 10-Town Study.

Competing interests: None.

\section{REFERENCES}

1. Cats-Baril WL, Frymoyer JW. The economics of spinal disorders. In: The adult spine: principles and practice. New York: Raven Press, 1991.

2. Department for Work and Pensions. Department of Social Security/Statistics. UK: DWP, 2006. Available at http://www.dwp.gov.uk/asd/ (accessed October 2006).

3. Social Insurance Institution. Statistical Yearbook of the Social Insurance Institution, Finland 2004. Helsinki: The Social Insurance Institution, 2005.

4. Finnish Centre for Pensions. Official Statistics of Finland/Social Protection/ Statistical Yearbook of Pensioners in Finland 2004. Helsinki: The Finnish Centre for Pensions, 2005.

5. Alexanderson K, Norlund A. Swedish Council on Technology Assessment in Health Care (SBU). Chapter 1. Aim, background, key concepts, regulations, and current statistics. Scand J Public Health Supp/ 2004;63:12-30. 
6. Norlund AI, Waddell G. Cost of back pain in some OECD countries. In: Nachemson AL, Jonsson E, eds. Neck and back pain, the scientific evidence of causes, diagnosis, and treatment. Philadelphia, USA: Lippincott Williams and Wilkins, 2000:421-5.

7. van Tulder MW, Goossens ME, Hoving J. Nonsurgical treatment of chronic neck pain. In: Nachemson AL, Jonsson E, eds. Neck and back pain, the scientific evidence of causes, diagnosis and treatment. Philadelphia, USA: Lippincott Williams and Wilkins, 2000:339-54.

8. van Tulder MW, Goossens ME, Waddell G, et al. Conservative treatment of chronic low back pain. In: Nachemson AL, Jonsson E, eds. Neck and back pain, the scientific evidence of causes, diagnosis, and treatment. Philadelphia, USA: Lippincott Williams and Wilkins, 2000:271-304.

9. Guzman J, Esmail R, Karjalainen K, et al. Multidisciplinary rehabilitation for chronic low back pain: systematic review. BMJ 2001 23;322:1511-16.

10. Vahtera J, Kivimaki M, Pentti J, et al. Organisational downsizing, sickness absence, and mortality: 10-town prospective cohort study. BMJ 2004 6:328:555.

11. Mayer TG, Gatchel RJ, Kishino N, et al. Objective assessment of spine function following industrial injury. A prospective study with comparison group and one-year follow-up. Spine 1985;10:482-93.

12. Vahtera J, Pentti J, Kivimäki M. Sickness absence as a predictor of mortality among male and female employees. J Epidemiol Community Health 2004;58:321-6.

13. Marmot M, Feeney A, Shipley M, et al. Sickness absence as a measure of health status and functioning: from the UK Whitehall II study. J Epidemiol Community Health 1995;49:124-30.

14. Guidelines for ATC classification and DDD assignment. Oslo: WHO Collaborating Centre for Drug Statistics Methodology, 2006.
15. Lipsitz SR, Kim K, Zhao L. Analysis of repeated categorical data using generalized estimating equations. Stat Med 1994;13:1149-63.

16. Nachemson AL, Waddell G, Norlund Al. Epidemiology of neck and low back pain. In: Nachemson AL, Jonsson E, eds. Neck and back pain, the scientific evidence of causes, diagnosis, and treatment. Philadelphia, USA: Lippincott Williams and Wilkins, 2000:165-87.

17. Kivimaki M, Forma P, Wikstrom J, et al. Sickness absence as a risk marker of future disability pension: the 10-town study. J Epidemiol Community Health 2004;58:71011.

18. Kivimäki M, Head J, Ferrie JE, et al. Sickness absence as a global measure of health: evidence from mortality in the Whitehall II prospective cohort study. BMJ 2003:327:364-8.

19. Bendix AE, Bendix T, Haestrup C, et al. A prospective, randomized 5-year follow-up study of functional restoration in chronic low back pain patients. Eur Spine J 1998:7:111-19.

20. Harkapaa K, Mellin G, Jarvikoski A, et al. A controlled study on the outcome of inpatient and outpatient treatment of low back pain. Part III. Long-term follow-up of pain, disability, and compliance. Scand J Rehabil Med 1990;22:181-8

21. Lindh $\mathbf{M}$, Lurie $\mathbf{M}$, Sanne $H$. A randomized prospective study of vocational outcome in rehabilitation of patients with non-specific musculoskeletal pain: a multidisciplinary approach to patients identified after 90 days of sick-leave. Scand J Rehabil Med 1997;29:103-12.

22. Gross AR, Aker PD, Goldsmith CH, et al. Physical medicine modalities for mechanical neck disorders (Cochrane Review). The Cochrane Library, 2000(2).

\section{Committee on Publication Ethics (COPE) - Seminar 2008}

\subsection{0am-4.30pm Friday 4 April 2008, Woburn House, London, UK}

This year's seminar will focus on three key topics: (1) How does patient privacy legislation affect an editor's ability to publish? (2) What is publication? - the changing definitions of publication. (3) COPE's new Best Practice Guidelines. There will also be a short demonstration of an anti-plagiarism system as it is working in a publishing house.

Invited speakers will discuss legislation on privacy and data protection that editors need to be aware of; how editors should respond to more and more data being available online prior to formal peer-reviewed publication; and what happens to a publication after it appears in print.

The newly designed COPE website will be demonstrated, and there will be interactive workshops on common ethical and editorial dilemmas.

Editors, authors and all those interested in improving the standard of publication ethics are welcome.

The seminar will include invited talks:

- A Pandora's box of tissues-legislation in relation to tissues and cells

- The promise and perils of patient privacy

- Pre-publication or duplicate publication? How to decide

- What really happens to a publication after it appears in print

- Screening for plagiarism: the CrossCheck initiative

In addition:

- Discussion of COPE's new Best Practice Guidelines with experiences from journals who have piloted the audit

- COPE's new website unveiled

- Interactive workshops on the key topics of the seminar.

- Opportunities to network with other editors and share your experiences and challenges

The seminar is free for COPE members and $£ 50.00$ for non-members. Numbers are limited and early booking is advisable. For registration or more information please contact the COPE Administrator at cope@bmjgroup.com or call 020-7383-6602.

For more information on COPE visit www.publicationethics.org.uk/ 